\title{
Product Design and Efficient Management of Recycling and Waste Treatment*
}

\author{
Thomas Eichner ${ }^{\dagger}$ and Rüdiger Pethig \\ Department of Economics, University of Siegen, Hoelderlinstr. 3, D-57068 \\ Siegen, Germany.
}

Proposed Running Head: Product Design and Recycling

*We are indebted to two anonymous referees for helpful comments.

†The corresponding author. Fax: +49-271-740 2732. E-mail: eichner@vwl.wiwi.unisiegen.de 


\begin{abstract}
Using a general equilibrium model where material is first extracted, then used for producing a consumption good, recycled and finally treated to reduce environmental damage, we study efficiency-restoring policies, when one or more of the constituent markets are inactive. The material is modeled as being embodied in the output and forms an important aspect of green product design. If all markets for embodied material per unit output fail and if recycling benefit exceeds environmental damage, the policy instruments needed for green design are a tax on the consumption good supply and a subsidy on the demand for material input.
\end{abstract}

Key words: Product design, recycling, waste treatment, material 


\section{Introduction}

Over the last decades, the generation and processing of solid household waste has become an increasing problem in many countries. Waste treatment prior to landfilling reduces or even avoids environmental damage and recycling prior to waste treatment kills two birds with one stone. It diminishes the environmentally detrimental flow of waste to be landfilled and it economizes on the use of scarce natural raw materials. Policy makers have recognized the benefits of recycling and are increasingly willing to foster it through new waste legislation and directives. Prominent cases in point are the German Green Dot program from 1990 and the Law on Circular Material Flows and Waste (Kreislaufwirtschafts- und Abfallgesetz) from $1996 .{ }^{1}$ In many other countries various policy initiatives have been directed towards stimulating recycling and reducing the waste flow. ${ }^{2}$

The principal theoretical issues involved in recycling and waste deposition are quite well understood. Since the 1970 s economists made the case for public resource and waste policy and suggested a great variety of policy instruments for discouraging waste generation and encouraging recycling. Essentially, the literature on recycling proceeded along three methodological lines: (i) dynamic models ranging from Smith [18], Lusky [10] to Highfill and McAsey [5] and Huhtala [8]; (ii) static partial equilibrium models ranging from Holterman [7], Miedema [11], Morris and Holthausen [12], Sigman [17], Palmer, Siegman and Walls [13] to Palmer and Walls [14]; (iii) static general equilibrium models ranging from Pethig [15], Kohn [9], Fullerton and Kinnaman [3], to Fullerton and Wu [4] and

\footnotetext{
${ }^{1}$ For more details see e.g. Rousso and Sha [16] and Holm-Mueller [6].

${ }^{2}$ Fullerton and $\mathrm{Wu}[4]$ survey the pertinent U.S. policy.
} 
Eichner and Pethig [2].

The present paper follows the last line of analysis based on a model in which a consumption good is produced by using the inputs labour and material where virgin and recycled material are considered homogeneous goods. The principal focus is on the efficient allocation of the product-related material flows thus capturing important aspects of product design and product life-cycle analysis. Among the few theoretical studies on 'green' product design is Fullerton and Wu [4] who introduce a product-design variable into their model which increases the cost of producing the consumption good and stimulates recycling, at the same time. This approach looks at green product design as improving the disassembly characteristics of the product. In contrast, the present paper interpretes product design as the product's composition of different materials. We explicitly assume that the material input forms part of the output, and we consider product design as a function of the embodied material per unit of output, called the material content, for short. Hence varying the material content means changing product design and that design remains an intrinsic attribute of the residuals left over after consumption. The material content of residuals, in turn, increases the productivity of recycling, and in this way the issue of an efficient product design arises.

In the present paper a further problem of efficient material flow is addressed at the next stage of material processing. Since recycling of material is necessarily incomplete, the recycling waste still contains some material that was embodied in the consumption residuals. Our model allows for the possibility that this 
'waste material' is environmentally harmful after being landfilled ${ }^{3}$ and that these detrimental environmental effects can be reduced through waste treatment prior to landfilling. If the material content of recycling waste affects the productivity of waste treatment, which is a plausible hypothesis, then the issue of an efficient choice of material content of recycling waste arises.

Putting this approach into the context of previous work we observe that the links are closest to Kohn [9], Fullerton and Kinnaman [3], Fullerton and Wu [4] and Eichner and Pethig [2]. Kohn [9] ignores the embodied material issue which is the central focus here. Fullerton and Kinnaman [3] as well as Fullerton and Wu [4] do not model recycling as a technology that generates the output 'recycled material' by expending scarce resources (labour). They rather view recycling as a costless household activity of separating or decomposing consumption waste, and they do not focus on recycled material and waste treatment.

Except for Eichner and Pethig [2] the literature does not model the material flow through the successive stages of processing as outlined above in a way consistent with material balance considerations. When we do so in the present paper, the principle focus turns out to be on the material content of the consumption good, the material content of consumption residuals and the material content of

${ }^{3}$ Environmental damage may be due to pollutants released from the landfill into the air (gas) or the ground (seepage) and/or due to deterioration of ecological systems through landfilling. Toxid and hazardous waste is a prime candidate for treatment prior to deposition while waste containing metals is bound for recycling. Plastics in waste is ambiguous; it may be reused (downcycled) or treated e.g. incinerated. If some waste material, like perhaps glass, is not environmentally harmful at all, our model would imply that the efficient scale of treatment prior to landfilling is zero. 
recycling waste. We first take up the issue of establishing a system of competitive markets for an efficient allocation of material and material content. More specifically, prices depend on material content in all markets where material content is a relevant product characteristic. In this way, an efficient product design is induced by appropriate price signals being transmitted back to producers. But for various reasons, markets for consumption residuals and solid waste may lack incentives to work smoothly. Hence the question arises what the policy options are to restore efficiency if one or more of those markets should fail. The paper's main attention is focused on the capacity of taxes or subsidies to induce an efficient product design as a substitute of absent or incomplete markets.

The paper is organized as follows. Section 2 outlines the model. In Section 3 we derive the basic properties of the efficient allocation which is decentralized in Section 4 by means of a market system with a complete set of competitive markets. Section 5 proceeds to investigate various corrective tax-subsidy schemes in case some markets fail to operate smoothly. 


\section{The Model}

Suppose a single consumption good $X$ is supplied by the production sector in quantity $x^{s}$ according to the strictly increasing, concave production function ${ }^{4}$

$$
x^{s} \leq X\left(\ell_{x}^{d}, m^{d}\right)
$$

Good $X$ is produced with labour, $\ell_{x}^{d}$, and with two types of material which are embodied in the output. For simplicity, one of these materials is assumed to be costless and (therefore) not explicitly introduced into the formal model. The other type of material, referred to as material, for short, is an explicit input in (1); its quantity is $m^{d}$. Each unit of good $X$ is of constant weight, but the technology (1) allows for varying the material input mix (and hence the materials composition of output) as measured by the material-output ratio

$$
q_{x}^{s}:=\frac{m^{d}}{x^{s}}
$$

i.e. the share of (the explicitly modeled) material per unit of output $X$. We will call $q_{x}^{s} \in(0,1]$ the material content of good $X$.

After $x^{d}$, the quantity demanded of good $X$, is consumed, it is turned into residuals of equal weight which are denoted by $z$. These residuals are supplied to the recycling sector which uses the residuals, $z^{d}$, labour, $\ell_{r}^{d}$, and the material

${ }^{4}$ The model (1)-(14) is presented in an aggregate form to keep complexity tractable. Some significant consequences of expanding the number of consumers, recycling firms and/or waste treatment firms are investigated by Eichner and Pethig [2].

${ }^{5}$ In (1) the superscript $s$ and $d$ indicate quantities supplied and demanded, respectively, and this scheme is consistently applied to all economic variables. Upper-case letters are reserved to denote functions and subscripts attached to them indicate first derivatives. 
content of residuals, $q_{r}^{d}$, as inputs to generate secondary material, $r^{s}$, with the help of the strictly increasing, concave recycling function

$$
r^{s} \leq R\left(\ell_{r}^{d}, q_{r}^{d}, z^{d}\right)
$$

Similar as Pethig [15], Dinan [1] and Kohn [9] but in contrast to Fullerton and Wu [4] we assume in (3) that the use of labour, $\ell_{r}^{d}$, is necessary for regaining material from residuals. Following Eichner and Pethig [2] the material content of residuals, $q_{r}^{d}$, is considered an argument of the recycling function which is novel and will be shown to be central to our policy analysis below. An increase in the attribute $q_{r}^{d}$ of residuals improves their 'recyclability'. ${ }^{6} R_{q}>0$ is indispensible on grounds of material balance, and these considerations also require that the transformation of residuals into recycled material is bounded by $\lim _{\ell_{r}^{d} \rightarrow \infty} R\left(\ell_{r}^{d}, q_{r}^{d}, z^{d}\right)<q_{r}^{d} z^{d}$.

The recycling process generates two outputs, recycled material, $r^{s}$, and recycling waste, $f^{s}$, which add up to $z^{d}$ in terms of weight

$$
f^{s}:=z^{d}-r^{s}
$$

Moreover, since recycling of residuals is necessarily incomplete the material content of recycling waste

$$
q_{f}^{s}:=\frac{q_{r}^{d} z^{d}-r^{s}}{f^{s}}
$$

is strictly positive, though possibly small. By assumption, the recycling waste has the potential of causing environmental damage if landfilled without prior waste treatment. Following Eichner and Pethig [2] the waste treatment technology is

${ }^{6}$ As already mentioned in the introduction Fullerton and Wu [4] consider a variable for 'recyclability' which is not linked to material flows. 
given by the convex function $E$ satisfying

$$
e \geq E\left(\ell_{f}^{d}, q_{f}^{d}, f^{d}\right)
$$

with $E_{\ell}<0, E_{f}>0$ and $E_{q}>0$. In $(6), e$ is an index of environmental degradation caused by landfilled waste after treatment (see footnote 3 ), referred to as emissions, for convenience. Primary material is extracted with the help of the strictly increasing, concave production function

$$
v^{s} \leq V\left(\ell_{v}^{d}\right)
$$

The representative consumer's quasi-concave utility function is

$$
u \leq U\left(e, \ell^{s}, x^{d}\right)
$$

with $U_{e}<0, U_{\ell}<0$ and $U_{x}>0$. $\ell^{s}$ is the consumer's endogenous labour supply, $x^{d}$ is her demand for good $X$, and $e$ is the pollution not eliminated through waste treatment. The description of the model is completed by the following constraints:

$$
\begin{gathered}
x^{s} \geq x^{d}, \quad v^{s}+r^{s} \geq m^{d}, \quad \ell^{s} \geq \ell_{x}^{d}+\ell_{r}^{d}+\ell_{f}^{d}+\ell_{v}^{d}, \\
x^{d}=z^{s}, \\
z^{s}=z^{d}, \\
f^{d} \geq f^{s}, \\
q_{x}^{s}=q_{h}^{d}=q_{h}^{s}=q_{r}^{d},
\end{gathered}
$$




$$
q_{f}^{d} \geq q_{f}^{s}
$$

(9) presents conventional resource constraints relating, respectively, to the supply of good $X$, the material supply (implying that primary und recycled material are perfect substitutes), and the labour supply. The constraints (9)-(14) imply a specific pattern (and sequence) of transactions: firm $X$ offers $\left(x^{s}, q_{x}^{s}\right)$ to the consumer whose demand is $\left(x^{d}, q_{h}^{d}\right)$; the consumer then offers the residuals from good $X\left(z^{s}, q_{h}^{s}\right)$ to the recycler whose demand is $\left(z^{d}, q_{r}^{d}\right)$; after recycling, the recycler passes the recycling waste $\left(f^{s}, q_{f}^{s}\right)$ on to the waste treatment firm whose demand is $\left(f^{d}, q_{f}^{d}\right)$; after waste treatment, the (recycling) waste is costlessly landfilled.

This pattern of transactions is interpreted as reflecting a particular arrangement of property rights under which consumers acquire the quantity, $x^{d}$, as their property when purchasing good $X$ for consumption. As a consequence they are responsible for the proper disposal of all residuals left over after consumption, i.e. they are responsible for handing over all residuals to the recycler. ${ }^{7}$ Implicitly, the equality and inequality signs of (9)-(14) secure that all residuals end up as input in the recycling process and that all recycling waste is turned into an input in the waste treatment process. This feature of the model is maintained when various policies are discussed in Section 5. Even though some of these policies are known to encourage illegal dumping (see e.g. Fullerton and Kinnaman [3]), the cost of

${ }^{7}$ There is an alternative property-rights scheme, the so called take back rule, in which the consumer returns the residuals to the firm $X$ (at zero price) who then sells them along with the material content of residuals to the recycling firm. Investigating the impact of the take back rule is beyond the scope of the present paper. For more details see Eichner and Pethig [2] who show that in the absence of property-rights-specific costs both regimes are equivalent. 
enforcement is assumed to be zero for the purpose of the present paper.

Before we proceed with the theoretical discussion, some remarks are in order about how our model relates to real-world solid waste management issues. When thinking of good $X$, durable consumption goods come immediately to one's mind, e.g. automobiles, refridgerators etc. To some extend, their material composition can be varied, but producers have no incentives to consider aspects of 'design for recycling' or 'design for environment' unless appropriate price signals are transmitted back to them. Quite a different example is packaging. The material input $\left(m^{d}\right)$ might be thought of as plastic, aluminum, glass, paper etc. used for packaging. When collected from the households packaging residuals are composed of a mix, and in that case the recycling technology (3) is rather a separation technology. No doubt, the entire complexity of packaging waste is not captured in the model, but in a stylized way two of its important features are addressed: Incentives to reduce its volume as well as to change its material composition for stimulating recyclability and for reducing environmental damage caused by packaging waste deposition.

The model (1)-(14) may be considered quite restrictive in that it requires mandatory recycling and waste treatment in two successive stages of waste processing. For such a setting, the German Green Dot program is, perhaps, an approximate case in point, but other empirical examples are hard to find; waste deposition without recycling and/or waste treatment appears to be widespread. However, the model is not as rigid as it may appear: First, no presumption has been made regarding recycling quotas or minimum waste treatment standards; hence mandatory waste processing is largely a formal requirement. Second, the 
model includes as 'corner solutions' the polar cases (i) where the waste flow passes through the recycling sector without any recycling taking place (because primary material extraction is less costly) and (ii) where the recycling waste passes through the waste treatment facility, but leaves it untreated (because the waste treatment costs would exceed the environmental damage which covers all those cases where solid waste deposition does not cause any environmental damage at all).

\section{The Efficient Allocation}

In this section we focus on the Pareto optimal allocation which follows from solving the Lagrangean:

$$
\begin{gathered}
\mathcal{L}=U\left(e, \ell^{s}, x^{d}\right)+\pi_{x}\left[X\left(\ell_{x}^{d}, m^{d}\right)-x^{s}\right]+\lambda_{x}\left(x^{s}-x^{d}\right)+\lambda_{f}^{s}\left(f^{s}-z^{d}+r^{s}\right)+\lambda_{g}^{s}\left(x^{d}-z^{s}\right) \\
+\lambda_{z}\left(z^{s}-z^{d}\right)+\lambda_{f}\left(f^{d}-f^{s}\right)+\lambda_{\ell}\left[\ell^{s}-\ell_{x}^{d}-\ell_{r}^{d}-\ell_{f}^{d}-\ell_{v}^{d}\right]+\pi_{v}\left[V\left(\ell_{v}^{d}\right)-v^{s}\right]+\lambda_{m}\left(v^{s}+r^{s}-m^{d}\right) \\
+\lambda_{e}\left[e-E\left(\ell_{f}^{d}, q_{f}^{d}, f^{d}\right)\right]+\lambda_{t}\left(q_{f}^{s} f^{s}-q_{r}^{d} z^{d}+r^{s}\right)+\lambda_{q f}\left(q_{f}^{d}-q_{f}^{s}\right)+\lambda_{C}\left(\frac{m^{d}}{x^{s}}-q_{x}^{s}\right)+\lambda_{q h}\left(q_{x}^{s}-q_{h}^{d}\right) \\
+\lambda_{q c}\left(q_{h}^{s}-q_{r}^{d}\right)+\lambda_{D}\left(q_{h}^{d}-q_{h}^{s}\right)+\pi_{r}\left[R\left(\ell_{r}^{d}, q_{r}^{d}, z^{d}\right)-r^{s}\right] .
\end{gathered}
$$

Along the lines of Eichner and Pethig [2] it can be shown that a solution to (15) exists. If we impose, in addition, the plausible assumptions $X\left(0, m^{d}\right)=0, V(0)=$ $0, R\left(\ell_{r}^{d}, q_{r}^{d}, 0\right)=0, R\left(0, q_{r}^{d}, z^{d}\right)=0, R\left(\ell_{r}^{d}, 0, z^{d}\right)=0, \lim _{\ell_{r}^{d} \rightarrow \infty} R\left(\ell_{r}^{d}, q_{r}^{d}, z^{d}\right)<q_{r}^{d} z^{d}$ $E\left(0, f^{d}, q_{f}^{d}\right)>0$ for $f^{d}>0, q_{f}^{d}>0$, and $r^{s}>0$, it turns out that in the solution all economic variables are strictly positive, except for $e \geq 0$ and $\ell_{f} \geq 0$, and that all Lagrange multipliers are strictly positive except for $\lambda_{g}^{s}, \lambda_{z}, \lambda_{q h}, \lambda_{q c}, \lambda_{D}$, and $\lambda_{C}$. If $R_{q}$ and $R_{z}$ converge to zero (material extraction dominates recycling) 
these Lagrange multipliers are strictly negative. On the other hand, if $E_{q_{f}}$ and $E_{f}$ converge to zero (landfilled waste does not cause pollution) they are strictly positive. Moreover, if $E_{q_{f}} \rightarrow 0$ and $E_{f} \rightarrow 0$ the Lagrange multipliers $\lambda_{f}, \lambda_{q f}, \lambda_{f}^{s}$ and $\lambda_{t}$ tend to zero.

The FOCs listed in the first column of table I can be rearranged to yield:

Proposition 1. (Properties of the efficient allocation):

(i) The efficient allocation of the economy (1)-(14) is characterized by

$$
\begin{gathered}
\frac{U_{e}}{U_{\ell}}=-\frac{1}{E_{\ell}} \\
\frac{R_{q}}{R_{\ell}}+\frac{E_{q_{f}}}{E_{\ell}} \frac{z}{f}=-\frac{x A}{X_{\ell}} \quad \text { where } A:=\left(X_{m}-\frac{X_{\ell}}{V_{\ell}}\right), \\
-\frac{U_{x}}{U_{\ell}}=\frac{1}{X_{\ell}}-\frac{R_{z}}{R_{\ell}}+\frac{R_{q}}{R_{\ell}} \frac{q}{z}-\frac{E_{f}}{E_{\ell}}+\frac{E_{q_{f}}}{E_{\ell}} \frac{q_{f}}{f}
\end{gathered}
$$

(ii) If $E\left(\ell_{f}^{d}, q_{f}^{d}, f^{d}\right)=\tilde{E}\left(\ell_{f}^{d}, q_{f}^{d} f^{d}\right)$ and $R\left(\ell_{r}^{d}, q_{r}^{d}, z^{d}\right)=\tilde{R}\left(\ell_{r}^{d}, q_{r}^{d} z^{d}\right)$, then (18) is turned into

$$
-\frac{U_{x}}{U_{\ell}}=\frac{1}{X_{\ell}}
$$

(iii) Suppose the production function is linear homogeneous and the function $V$ is linear. Then there is a strictly decreasing function $\varphi$ such that $q=\varphi(A)$ is the efficient material content per unit of output.

(iv) The Lagrange multipliers have the following properties:

If $E\left(\ell_{f}^{d}, q_{f}^{d}, f^{d}\right)=\tilde{E}\left(\ell_{f}^{d}, q_{f}^{d} f^{d}\right)$ and $R\left(\ell_{r}^{d}, q_{r}^{d}, z^{d}\right)=\tilde{R}\left(\ell_{r}^{d}, q_{r}^{d} z^{d}\right)$, then

$$
\frac{\mu_{f}}{q_{f}}=\frac{\mu_{q f}}{f} \quad \text { and } \quad \frac{\mu_{z}}{q}=\frac{\mu_{q h}}{z}
$$

(where $\mu_{f}:=\lambda_{f} / \lambda_{\ell}, \mu_{z}:=\lambda_{z} / \lambda_{\ell}$ etc.). Otherwise (20) does not hold, in general. 
Proposition 1 is proved in the appendix. Equation (16) represents the rule for the efficient allocation of pollution. It requires the marginal environmental damage (LHS) and the marginal waste treatment costs (RHS) to be equal. Similarly, equation (17) governs the efficient allocation of material content $q$ and $q_{f}$. A single equation suffices to determine both $q$ and $q_{f}$ because due to $(5) q_{f}$ is linearly dependent on $q$. The LHS of (17) is the sum of the marginal benefit from recycling by increasing $q$ and of the marginal damage from a small increase in $q_{f}$ weighted with the ratio of residuals to recycling waste $(z / f)$. The RHS of (17) represents the associated marginal costs, a distortion in the production of good $X$. This distortion consists of the divergence between the indirect marginal labour productivity, $X_{m} V_{\ell}$, and the direct marginal productivity, $X_{\ell}$. Clearly, since the marginal benefit from recycling and the marginal damage from waste treatment (LHS of (17)) are opposite in sign, the sign of the production distortion, $A$, depends on whether or not the recycling benefits of a small increase in material content, $q$, overcompensate the marginal environmental damage of that increase.

Equation (18) determines the efficient allocation of good $X$ which is attained, if the representative consumer's marginal willingness-to-pay for good $X$ in terms of labour, $-U_{x} / U_{\ell}$, equals the sum of marginal production costs, $1 / X_{\ell}$, marginal environmental damage, $\left(-E_{f} / E_{\ell}+E_{q_{f}} q_{f} / E_{\ell} f\right)$, and marginal recycling benefits, $\left(-R_{z} R_{\ell}+R_{q} q / R_{\ell} z\right) .{ }^{8}$ It is interesting to note that both marginal environmental

${ }^{8}$ Recall that the signs of $\mu_{q c}:=\lambda_{q c} / \lambda_{\ell}$ and $\mu_{z}:=\lambda_{z} / \lambda_{\ell}$ are indeterminate. It can be shown that $\mu_{q c}=\frac{R_{q}}{R_{\ell}}+\frac{E_{q_{f}}}{E_{\ell}} \frac{z}{f}$ and that $\mu_{z}-\mu_{q h} \frac{q}{z}=\frac{R_{z}}{R_{\ell}}-\frac{R_{q}}{R_{\ell}} \frac{q}{z}+\frac{E_{f}}{E_{\ell}}-\frac{E_{q_{f}}}{E_{\ell}} \frac{q_{f}}{f}$. Then $\mu_{q c}$ displays the marginal benefit and damage from increasing material content in recycling and 
damage and marginal recycling benefits are composed of two partial effects which are opposite in sign. The greater the material content $q$ and $q_{f}$ the greater are the countervailing effects $E_{q_{f}} q_{f} / E_{\ell} f$ and $R_{q} q / R_{\ell} z$.

Proposition 1(ii) shows that (18) is turned into the simple equation (19) if the recycling and waste treatment technology take on the special functional form $\tilde{R}$ and $\tilde{E}$, respectively. The interpretation of $\tilde{R}$ and $\tilde{E}$ is straightforward. In case of $\tilde{E}$ pollution is caused exclusively by the amount of the (explicitly modeled) material that is embodied in recycling waste, while the other type of material is environmentally neutral. Similarly, in case of $\tilde{R}$ the productivity of recycling depends exclusively on the amount of the (explicitly modeled) material embodied in residuals, while the other type of material neither alleviates nor renders more difficult the process of recycling. Hence the rationale of proposition 1 (ii) is that if $q, q_{f}, z$ and $f$ have an allocative impact through the embodied material $q z$ and $q_{f} f$ only then good $X$ is not involved in any material-related externality, and hence its efficient allocation is ruled by the same marginal condition as in case of the absence of recycling and waste treatment. Note also that $E=\tilde{E}$ and $R=\tilde{R}$ (hence (19)) do not imply $A=0$ in (17). The attention directed here to the special functional forms $\tilde{R}$ and $\tilde{E}$ is motivated by their important role for policy conclusions in the subsequent analysis.

To clarify the great economic-environmental relevance of proposition 1(iii), observe first that $E_{q_{f}}=0$ and $R_{q}=0$ is sufficient (but not necessary) for $A=0$. To fix our ideas define $q^{0}=\varphi(A)$ for $A=0$. Since $\varphi$ is strictly decreasing we waste treatment (see the LHS of equation (17)) and $\mu_{z}-\mu_{q h} \frac{q}{z}$ reflects total marginal recycling benefit and total marginal environmental damage. 
obviously have

$$
q\{\gtreqless\} q^{\circ} \quad \Longleftrightarrow \quad A\{\lesseqgtr\} 0
$$

Clearly, $q=q^{\circ}$ is a benchmark value of $q$ that is efficient in an economy where waste treatment and recycling is technically infeasible. If we compare that economy with one satisfying $E_{q_{f}}>0$, but $R_{q}=0$, then (17) yields $A>0$, hence $q<q^{\circ}$. For the other polar case $E_{q_{f}}=0$, but $R_{q}>0$ (17) implies $A<0$, hence $q>q^{\circ}$. Finally, if both $E_{q_{f}}>0$ and $R_{q}>0$, the LHS of (17) exhibits two effects in opposite directions so that the sign of $A$ depends on the relative strength of the partial effects. The important insight is that the environmental externality calls for reducing the material content per unit of output of good $X$ while recycling calls for increasing it, ceteribus paribus. The latter observation is straightforward because increasing the material content makes recycling easier by reducing the effort (labour input) of regaining material from a given amount of residuals. On the other hand, calling for a product design that increases the embodied material per unit of output to ease recycling is intriguing since recycling is meant to economize on the use of material. Note, however, that proposition 1(iii) leaves open the decisive question how the introduction of recycling affects the material throughput which is ultimately measured by the rate of extraction of primary material per period.

Proposition 1(iv) is somewhat technical in nature. Its importance becomes clear in proposition 2. 


\section{Efficiency of the Competitive Market Economy}

We now turn to the allocation of resources via competitive markets. Since the pollution issue is extensively treated in the literature we simply apply the perfectly internalizing Pigouvian emission tax, $t_{e}$, to the environmental externality in order to focus exclusively on the capacity of markets to allocate material efficiently. The method of investigation is to assume in this section that all markets under consideration work frictionless while Section 5 investigates various taxsubsidy schemes regarding their capacity to restore efficiency when some (subset of) markets should lack incentives to be active. There are various ways how markets may handle the allocation of material content which are investigated in some detail by Eichner and Pethig [2]. For the purpose of the present paper it suffices, however, to refer to a system of five markets which are represented in column 2 of table II by their respective market prices. While the markets for labour $\left(p_{\ell}\right)$ and material $\left(p_{m}\right)$ are conventional competitive markets the other three exhibit prices (i.e. price functions, technically speaking) that depend on the material content of the good traded. Through the dependence of the price on material content the markets for good $X$, for residuals and for recycling waste are, at the same time, indirect markets for those commodities' material content. This concept of indirect markets for material content first introduced by Fullerton and Wu [4] in a somewhat different context reflects indirectly the agents' positive or negative valuation of material content in the prices of the good under consideration. Knowing about the dependence of prices on material content, agents express supplies and demands for material content that need to match in market equilibrium. 
Table II does not only define competitive markets as represented by their prices (column 2) and the associated market transactions (column 1), but also a set of (potential) tax and subsidy rates (column 3) with their respective bases (column 1). Although the policy issue of restoring efficiency in case of market failure is not addressed in the present section, we do consider all policy instruments listed in table II when formalizing the agents' optimization problems in the next step for the convenience of avoiding later repetition.

As a necessary condition for a competitive equilibrium of the market economy of table II each agent has to solve an optimization problem as specified by the following Lagrangeans (21)-(25): ${ }^{9}$.

$$
\begin{gathered}
\tilde{\mathcal{L}}^{H}=U\left(e, \ell^{s}, x^{d}\right)+\gamma_{c}\left[p_{\ell} \ell^{s}+\phi+\left(P^{z}\left(q_{h}^{s}\right)+\sigma_{z}\right) z^{s}+\sigma_{q c} q_{h}^{s}-\left(P^{x}\left(q_{h}^{d}\right)+\tau_{x}\right) x^{d}-\tau_{q h} q_{h}^{d}\right] \\
+\gamma_{q}^{h}\left(q_{h}^{d}-q_{h}^{s}\right)+\gamma_{g}^{s}\left(z^{s}-x^{d}\right) \\
\tilde{\mathcal{L}}^{P}=\left(P^{x}\left(q_{x}^{s}\right)+\sigma_{x}\right) x^{s}+\sigma_{q h} q_{x}^{s}-p_{\ell} \ell_{x}^{d}-\left(p_{m}+\tau_{m}\right) m^{d}+\gamma_{x}\left[X\left(\ell_{x}^{d}, m^{d}\right)-x^{s}\right] \\
+\gamma_{q}\left(q_{x}^{s}-\frac{m^{d}}{x^{s}}\right) \\
\tilde{\mathcal{L}}^{E}=-t_{e} e-p_{\ell} \ell_{f}^{d}-\left(P^{f}\left(q_{f}^{d}\right)+\tau_{f}\right) f^{d}-\tau_{q f} q_{f}^{d}+\gamma_{e}\left[e-E\left(\ell_{f}^{d}, q_{f}^{d}, f^{d}\right)\right] \\
\tilde{\mathcal{L}}^{R}=\left(p_{m}+\sigma_{m}\right) r^{s}-p_{\ell} \ell_{r}^{d}-\left(P^{z}\left(q_{r}^{d}\right)+\tau_{z}\right) z^{d}-\tau_{q c} q_{r}^{d}+\left(P^{f}\left(q_{f}^{s}\right)+\sigma_{f}\right) f^{s}+\sigma_{q f} q_{f}^{s}
\end{gathered}
$$

${ }^{9}$ Each sector is abbreviated by its first letter in order to mark the Lagrangeans, e.g. the recycling sector solves the optimization problem $\tilde{\mathcal{L}}^{R}$. In (21) $\phi$ is a lumpsum transfer of profits and of the net tax revenue to the representative household. The notation in the Lagrangeans follows the usual convention that revenues or incomes are received from sales (price times quantity sold) and costs or expenditures are incurred from purchases (prices times quantity bought) independent of whether the associated prices are positive or negative. 


$$
\begin{gathered}
+\gamma_{r}\left[R\left(\ell_{r}^{d}, q_{r}^{d}, z^{d}\right)-r^{s}\right]+\gamma_{f}\left(f^{s}-z^{d}+r^{s}\right)+\gamma_{q f}\left(q_{f}^{s}-\frac{q_{r}^{d} z^{d}-r^{s}}{f^{s}}\right), \\
\tilde{\mathcal{L}}^{V}=p_{m} v^{s}-p_{\ell} \ell_{v}^{d}+\gamma_{v}\left[V\left(\ell_{v}^{d}\right)-v^{s}\right] .
\end{gathered}
$$

Quite obviously, the price vector $p:=\left[p_{\ell}, p_{m}, P^{x}(q), P^{z}(q), P^{f}\left(q_{f}\right)\right]$ and the allocation resulting from solving (21)-(25) constitute a competitive general equilibrium, if all constraints in (9), (12) and (14) hold as equalities. We are now in the position to demonstrate, what the capacity of the market economy is to achieve allocative efficiency in equilibrium if the government abstains from imposing any taxes or subsidies (except for the perfectly internalizing tax $t_{e}$ ).

\section{Proposition 2. (Efficiency of the market economy):}

Set all policy parameters $\tau$ and $\sigma$ equal to zero in (21)-(25), and set $p_{\ell} \equiv 1, p_{m}=$ $\mu_{m}, P^{x}(q)=\mu_{x}, P^{z}(q)=\mu_{z}, P^{f}\left(q_{f}\right)=-\mu_{f}, P_{q}^{x}=P_{q}^{z}=\frac{\mu_{q h}}{x}=\frac{\mu_{q c}}{z}, P_{q_{f}}^{f}=-\frac{\mu_{q f}}{f}$, and $t_{e}=\mu_{e}$. Then a competitive general equilibrium is attained and the pertinent allocation is efficient.

To prove proposition 2 observe that the FOCs of the Lagrangeans (21)-(25), are listed in column 2 of table I. When the prices as specified in proposition 2 are inserted into the FOCs of column 2 of table I and if all tax rates are set equal to zero, it is straightforward to show that column 2 is turned into column 1 of table I which characterizes the efficient allocation. It follows that the market economy is capable to support allocative efficiency, as claimed in proposition 2 .

It is very informative to see how prices guide the allocation in the market economy. The equilibrium prices for recycling waste, $P^{f}\left(q_{f}\right)$, and its derivative, 
$P_{q_{f}}^{f}$, are negative which is necessary for the waste treatment firm to become active. It follows that the recycling firm pays the amount $P^{f}\left(q_{f}^{s}\right) f^{s}$ for 'supplying' its recycling waste to the waste treatment firm. If the marginal recyling benefit overcompensates the marginal environmental damage, then the prices for residuals, $P^{z}(q)$, and its first derivative, $P_{q}^{z}$, are positive, and the consumer pays $P^{z}\left(q_{h}^{s}\right) z^{s}$ for 'supplying' her residuals to the recycling firm. On the other hand, if the marginal environmental damage exceeds the marginal recycling benefit, then $P^{z}(q)$ and its first derivative are negative and the recycling firm obtains the revenues $P^{z}\left(q_{r}^{d}\right) z^{d}$ for 'demanding' the consumer's residuals. All other prices are positive.

For the design of an effective environmental and resource management it is crucial to assess the empirical relevance of the market economy discussed above. It appears to have some empirical appeal but there is little reason to rely on the premise that all markets constituting this market economy operate sufficiently smoothly with low transaction costs to secure allocative efficiency. It is of utmost importance to know which markets can be expected to work in real economies because that information would be needed to suggest an appropriate solid waste management which should be one that enhances efficiency where markets fail, but does not intervene where markets operate reasonably well. Unfortunately, we are not aware of empirical investigations along the lines of our analytical framework that would provide clear-cut evidence about which markets can be expected to work or to fail. Candidates for failure are, first of all, those markets that clear at a negative price. Such a price cannot be sustained in laissez-faire if costless dumping is an option ('free disposal' in the conventional Debreu model) 
or if illegal dumping cannot be ruled out at low cost. It follows that the market for recycling waste in reality is not likely to work as smoothly as in the formal model (since $P_{q_{f}}^{f}<0$ ) and that the real market for residuals is likely to fail unless $P_{q}^{z}>0$. For most residuals (of durable consumption goods or packages) in the real economy the laissez-faire price is not positive after accounting for transactions cost.

Failure of the market for residuals or recycling waste may be complete in which case the market is not active at all or it may be partial in that (the non-zero) market price fails to reflect changes in the material content. Both types of market failure will be assumed in the next section in various combinations and a gallery of tax/subsidy schemes will be derived that are suitable, in the formal model, to restore efficiency. After that, some reflections are offered on the likely empirical relevance of market failure and on the expected transaction costs associated with different tax/subsidy schemes.

\section{Market Failures and Tax-Subsidy Schemes}

Since the main focus of the present paper is on the choice of material content as an issue of both product design and environmental control, we are particularly interested in the failure of those markets that are related to product design and material flows. As before, the environmental tax is kept at its Pigouvian level, $t_{e}=\mu_{e}$, throughout the rest of this paper which allows us to restrict our attention to the allocation of green product design. 
We take the market economy of Section 4 as a frame of reference and then assume that one or more of the constituent markets are failing thus rendering the truncated market system inefficient. More specifically, table III shows the markets for good $X$, residuals and recycling waste as candidates for failure, where failure either means that the respective market price is identically zero or that the (non-zero) price fails to depend on material content. The analysis proceeds by studying six different market failure scenarios listed in table III. The subsequent propositions 3 to 8 identify tax-subsidy schemes for each of these scenarios that bridge the efficiency gap caused by failing or missing market(s).

\subsection{No market for recycling waste}

In terms of the formal model the absence of markets for recycling waste means that $P^{f}\left(q_{f}\right) \equiv 0$ for all $q_{f} \geq 0$. Without any policy intervention, the consequence of this scenario is (i) that the recycling firm gets rid of its recycling waste (with whatever its material content is) free of charge and (ii) that the waste treatment firm does not spend any resources (labour) for waste treatment prior to landfilling. In other words, the inefficiency consists of either a failure of policy to make waste treatment mandatory or a failure to enforce mandatory waste treatment. To see what the potential remedies in terms of taxes and subsidies are we solve (21)-(25)

for $P^{f}=P_{q_{f}}^{f} \equiv 0$ without setting equal to zero all the $\sigma$ 's and $\tau$ 's as we did in the context of proposition 2. The results are summarized in

\section{Proposition 3.}

Suppose there is no market for recycling waste $\left(P^{f}=P_{q f}^{f} \equiv 0\right)$. 
(i) Set all other prices as in proposition 2 and set $\tau_{z}, \tau_{f}, \sigma_{f}, \sigma_{m}, \tau_{q c}, \tau_{q f}, \sigma_{q f}$ such

that these policy parameters satisfy $\tau_{f}=-\mu_{f}, \tau_{q f}=-\mu_{q f}$,

$\tau_{q c}-\left(\frac{z}{f}\right) \sigma_{q f}=\left(\frac{z}{f}\right) \mu_{q f}, \sigma_{m}-\sigma_{f}+\left(\frac{q_{f}-1}{f}\right) \sigma_{q f}=\mu_{f}-\left(\frac{q_{f}-1}{f}\right) \mu_{q f}$,

$\tau_{z}-\sigma_{f}-\left(\frac{q-q_{f}}{f}\right) \sigma_{q f}=\mu_{f}+\left(\frac{q-q_{f}}{f}\right) \mu_{q f}$.

(ii) Set $P^{z}=\mu_{z}+\tau_{x}$, set all other prices as in proposition 2 and set $\tau_{x}, \tau_{f}, \sigma_{f}$,

$\sigma_{m}, \tau_{q c}, \tau_{q f}, \sigma_{q f}$ such that these policy parameters satisfy $\tau_{f}=-\mu_{f}, \tau_{q f}=-\mu_{q f}$,

$\tau_{q c}-\left(\frac{z}{f}\right) \sigma_{q f}=\left(\frac{z}{f}\right) \mu_{q f}, \sigma_{m}-\sigma_{f}+\left(\frac{q_{f}-1}{f}\right) \sigma_{q f}=\mu_{f}-\left(\frac{q_{f}-1}{f}\right) \mu_{q f}$,

$\tau_{x}-\sigma_{f}-\left(\frac{q-q_{f}}{f}\right) \sigma_{q f}=\mu_{f}+\left(\frac{q-q_{f}}{f}\right) \mu_{q f}$

Then all markets clear and the pertinent allocation is efficient.

The set of all efficiency restoring tax-subsidy schemes listed in proposition 3 is disturbingly complex. The 'special cases' listed in table IV are of greater interest because they ignore all feasible convex combinations of policy instruments. From an analytical point of view, policy (a) is the most straightforward one because the missing equilibrium price $P^{f}\left(q_{f}\right)$ is simply replaced by a two-part waste treatment fee: the recycler has to pay $\sigma_{f}$ dollars per unit of recycling waste and $\sigma_{q f}$ per unit of its material content to the waste treatment firm which consequently receives $\tau_{f}=\sigma_{f}$ dollars per unit of recycling waste and $\tau_{q f}=\sigma_{q f}$ per unit of its material content. It is interesting to note that in view of proposition 3 and table IV the waste treatment firm has got to receive the two-part fee $\left(\tau_{f}, \tau_{q f}\right)$ as a necessary condition for any tax-subsidy scheme to restore efficiency.

The policies (b) and (c) have in common that the recycler needs no longer pay a two-part fee (as in policy (a)) but only pays for material content of recycling waste, $\sigma_{q f}$, while the quantity of that waste is passed on to the waste treatment 
firm free of charge. Hence there is no stick left to induce the recycler to keep the flow of recycling waste small. The policies (b) and (c) tell us that this missing stick can be replaced by (i) the carrot of subsidizing the recycled material output $\left(\sigma_{m}\right)$ and (ii) the stick of an additional tax which is not the same for both policies. Keeping the recycler's demand for residuals at the efficient level is achieved through policy (b) by levying a sales tax on residuals $\left(\tau_{z}\right)$ and through policy (c) by an equilibrium price of residuals, $p_{z}$, which is as high as the recycler's purchasing price of residuals in policy (b). Since the consumer can sell residuals at a high price under policy $(c)$ her purchase of good $X$ needs to be taxed $\left(\tau_{x}\right)$ to keep her utility maximizing calculus in line with efficiency.

Policy (d) deviates from policy (a) in a more straightforward way than the policies (b) and (c), since under that policy the recycler passes her recycling waste on to the waste treatment firm completely free of charge $\left(\sigma_{f}=\sigma_{q f}=0\right)$. Table IV shows that although the recycler does not pay any fees the correct incentives for efficiency are obtained by a very special mix of the policy parameters $\sigma_{m}, \tau_{x}$ and $\tau_{q c}$. When policy $(\mathrm{d})$ is compared with the results of previous contributions, e.g. Fullerton and Kinnaman [3] the divergencies are due to the impact of material content on recycling and waste treatment.

To compare our results with the work of Kohn [9] observe that proposition 3(ii) contains a hybrid policy, denoted policy ( $\left.\mathrm{c}^{\prime}\right)$, that is characterized by $P^{z}=\mu_{z}+\tau_{x}$, $\tau_{q f}=\sigma_{q f}=-\mu_{q f}, \tau_{f}=\sigma_{f}-\sigma_{m}=\sigma_{f}-\tau_{x}=-\mu_{f}$ and all other policy parameters zero. This particularly tax-subsidy scheme has been suggested by Kohn [9] for the special case $R_{q}=E_{q}=0$ implying $\tau_{q f}=\sigma_{q f}=-\mu_{q f}=0$. However, since $R_{q}=E_{q}=0$ is inconsistent with the requirement of material balance, 
$\tau_{q f}=\sigma_{q f}=-\mu_{q f}<0$ needs to be added to Kohn's tax-subsidy scheme to restore efficiency. (Alternatively, a market for material content of recycling waste must be assumed to be active). Observe also that when the possibilities of 'convex combinations' of policy parameters compatible with policy (c') are ignored policy (c') reduces either to policy (a) or to policy (c).

To sum up, the first basic message of proposition 3 is that in case the market for recycling waste does not work there is no efficiency-restoring tax-subsidy scheme which can do without choosing material content as a basis for taxes or subsidies. Second, (given the Pigouvian pollution tax) the waste treatment firm causes inefficiency unless it receives a two-part fee based on both the quantity of recycling waste and its material content. Third, the most appealing policy is to levy the two-part fee specified above in such a way that it is not only received by the waste treatment firm, but also paid by the recyclers who supply the recycling waste (policy (a)). Fourth, there are various ways to maintain efficiency when the recycler is partly or completely exempted from that fee. But due to the complexity of the compensating taxes and subsidies such substitute policies do not recommend themselves readily for practical waste policy.

\subsection{No market for residuals}

Suppose now that the market for residuals is not active: $P^{z}(q) \equiv 0$ for all $q \geq 0$. To investigate policy options for bridging this market failure we proceed as in the previous subsection by solving (21)-(25) for $P^{z}=P_{q}^{z} \equiv 0$. Rather than presenting a complete list of corrective tax-subsidy schemes (analogous to that in 
proposition 3) we put forward two policies which, in our view, give the necessary insight into the nature of the policy issue:

\section{Proposition 4.}

Suppose there is no market for residuals $\left(P^{z}=P_{q}^{z} \equiv 0\right)$.

(i) Set all other prices as in proposition 2 , set $\tau_{z}=\sigma_{z}=\mu_{z}, \tau_{q c}=\sigma_{q c}=\mu_{q c}$.

(ii) Set all prices as in proposition 2 , set $\tau_{q h}=-\mu_{q c}, \tau_{x}=-\mu_{z}$,

$\sigma_{q f}=-\left(\frac{f}{z}\right) \mu_{q c}, \quad \sigma_{f}=\left(\frac{q-q_{f}}{z}\right) \mu_{q c}-\mu_{z}, \sigma_{m}=\left(\frac{q-1}{z}\right) \mu_{q c}-\mu_{z}$.

Then all markets clear and the pertinent allocation is efficient.

The tax-subsidy scheme of proposition 4(i) is the direct analogue to policy (a) of table IV: The missing market for residuals is bridged by a two-part fee which is either paid by the households to the recyclers, if recycling is favorable relative to extraction and if the environmental damage is relatively small $\left(\mu_{z}>0\right.$ and $\left.\mu_{q c}>0\right)$ or which is paid by the recyclers to the households otherwise. Although this policy is quite simple, its practicability is more doubtful than that of policy (a) in the scenario of proposition 3, because one of the parties are the consumers. Due to their large numbers and the small amounts of good $X$ consumed by individual households, one would expect high administrative costs (which is likely to be the reason why no market emerges in the first place) and the risk of illegal dumping as in case of quantity related fees on household garbage.

This rather critical assessment of the policy outlined in proposition 4(i) suggests to ask whether an alternative corrective tax-subsidy scheme is available that can do without the policy instruments of proposition 4(i). Such an alternative 
exists, in fact, as proposition 4(ii) demonstrates. But unfortunately, the alternative scheme does not seem to improve upon the drawbacks of the former: It also involves two-part taxes on both households and recyclers levied at slightly different points in the materials flow. These two-part taxes are asymmetric and, moreover, need to be complemented by a tax or subsidy on recycled material $\left(\sigma_{m} \gtrless 0\right)$.

To fix our ideas suppose first, environmental damage is severe relative to the recycling benefits $\left(\mu_{z}<0\right.$ and $\left.\mu_{q c}<0\right)$. The missing (negative) price signals for residuals and its material content induce households to increase their supply of and induce the recycler to reduce her demand for residuals. Proposition 4(ii) reveals that the households' supply can be restrained through a tax on the consumption good $\left(\tau_{x}>0\right)$ which is equivalent to a tax on residuals. The recycler's demand for residuals $(z=f+r)$ can be stimulated, among other things, through a recycling subsidy $\left(\sigma_{m}>0\right)$. This is exactly the product tax coupled with a recycling subsidy which is often referred to as 'deposit-refund', see e.g. Palmer and Walls [14]. If however, recycling is favourable and environmental damage is small $\left(\mu_{z}>0\right.$ and $\left.\mu_{q c}>0\right)$, then incentives have to be set vice versa, and the policy of proposition 4(ii) encompasses, in fact, a product subsidy $\left(\tau_{x}<0\right)$ and a recycling tax $\left(\sigma_{m}<0\right)$ which is exactly the opposite to the deposit-refund system recommended in the literature .

Observe that as in the case of proposition 3 no corrective policy is available if material content of good $X$ or material content of recycling waste cannot be used as a tax base. This result is in stark contrast to Fullerton and Wu [4] whose model suggests a corrective policy for this type of market failure without 
using 'recyclability' as a tax base which corresponds to 'material content' in our model. The reason for this divergence is that in their model recycling is a costless activity of households whereas we assumed that material cannot be recycled without expending scarce resources (labour).

\subsection{No markets with prices depending on material content}

In the preceding subsections 5.1 and 5.2 we focused on the total shut-down of either the market for recycling waste or the market for residuals. It may be considered implausible to assume that some markets account for material content in their prices while others don't. Even though we are not in the position to settle that issue on the basis of sound empirical evidence, this plausibility argument seems to be supported by casual evidence, and therefore we now investigate four additional scenarios of market failure (see table III) whose common feature is that no market generates prices that depend on material content: $P_{q}^{x}=P_{q}^{z}=P_{q_{f}}^{f} \equiv 0$. The scenarios differ in that markets for residuals and/or recycling waste may or may not fail completely.

Before we proceed, some general remarks are in order. With reference to policy (a) in the context of proposition 3 and to proposition 4(i) we learnt that, whenever the market for recycled waste or residuals breaks down completely, a two-part fee, paid by one and received by the other side of the respective transactions, is suitable to replace the missing equilibrium price. As an alternative to such two-part fees, the government could impose tax and subsidy functions. that replace the missing price function $P(q)$ directly. Note, however, that we have no 
information about the shape of those price functions beyond their equilibrium values and first derivatives at equilibrium. Using two-part fees - or tax functions - as corrective policies remains an option in the four scenarios to be investigated below (see table III) when markets fail completely and when additional inefficiencies due to prices independent of material content are taken appropriate care of. Moreover, if only the dependence of prices on material content is missing $\left(P(q) \neq 0\right.$ but $\left.P_{q}=0\right)$, then appropriate 'one-part' fees do the job. For example, $\left(\sigma_{q h}, \tau_{q h}\right)$ with $\sigma_{q h}=\tau_{q h}=\mu_{q h}$ is such a fee in case of $P_{q}^{x}=0$.

As a consequence we already identified a set of rather simple and straightforward tax-subsidy policies for each of the last four market-failure scenarios listed in table III. We will not further formalize these policies below but, instead, restrict our attention to those corrective policies that do without tax functions and without the tax rates constituting two-part fees. Recall that this strategy of investigation rules out all tax or subsidy instruments which are based on material content. On the other hand, the four market scenarios to be studied in this section are such that prices are deprived of their capacity to direct material content towards efficiency, by assumption. It will be therefore interesting to see whether the resultant distortion can be corrected without using taxes based on material content.

\section{Proposition 5.}

Suppose that prices for good $X$, residuals and recycling waste do not depend on these commodities' respective material content $\left(P_{q}^{x}=P_{q}^{z}=\right.$ $\left.P_{q_{f}^{f}}^{f} \equiv 0\right)$. Set all prices as in proposition 2 , set $\sigma_{x}=-\left(\frac{q}{x}\right) \mu_{q h}, \tau_{m}=-\frac{\mu_{q h}}{x}$, 
$\sigma_{m}=\left(\frac{1-q_{f}}{f}\right) \mu_{q f}, \tau_{z}=\left(\frac{q-q_{f}}{f}\right) \mu_{q f}$. Then all markets clear and the pertinent allocation is efficient.

Proposition 5 restores efficiency through applying the policy $\left(\sigma_{m}, \tau_{z}\right)$ to the recycler and the policy $\left(\sigma_{x}, \tau_{m}\right)$ to the producer of good $X$. The recycler's sales of recycled material is subsidized $\left(\sigma_{m}>0\right)$ and her purchase of residuals as recycling input is taxed $\left(\tau_{z}>0\right)$. In this rather indirect way the efficient material content of recycling waste is induced. The regulation of the producer of good $X$ depends on the relative weight of the environmental externality. If recycling is favorable and environmental damage is small $\left(\mu_{z}>0\right.$ and $\left.\mu_{q c}>0\right)$, then the sales of good $X$ are taxed $\left(\sigma_{x}<0\right)$ and the purchase of material is subsidized $\left(\tau_{m}<0\right)$. With heavy environmental damage $\left(\mu_{z}<0\right.$ and $\left.\mu_{q c}<0\right)$, taxation and subsidization is reversed. In the former situation the labour intensity of producing good $X$ tends to fall and the material content of good $X$ increases. The opposite shift occurs in the latter case. Note that embedded in the policy of proposition 5 is of a deposit-refund scheme, if environmental damage is small but otherwise a 'reversed' deposit-refund scheme is applied.

Since the tax-subsidy scheme of proposition 5 does not rely on material content as a tax base, and since all prices have been assumed to be independent of material content, all agents who had a demand for or a supply of material content in the full-scale market economy are now indifferent regarding the size of material content. It is an interesting message of proposition 5 that price and tax signals relating directly to material content are not necessary for efficient green product design. But on the other hand, the break-down of all price signals for material 
content requires a fairly sophisticated tax-subsidy regulation whose implementation is certainly difficult due to informational requirements to determine the appropriate tax/subsidy rates.

The next step is to investigate possible remedies for the case that all market prices are independent of material content and that, in addition, the market for recycling waste fails completely (see table III).

\section{Proposition 6.}

Suppose that prices for good $X$ and for residuals do not depend on material content and that there is no market for recycling waste at all $\left(P_{f}=\right.$ $\left.P_{q_{f}}^{f}=P_{q}^{x}=P_{q}^{z} \equiv 0\right)$. Set all prices as in proposition 2 , set $\sigma_{x}=-\left(\frac{q}{x}\right) \mu_{q h}$, $\tau_{m}=-\frac{\mu_{q h}}{x}, \tau_{f}=-\mu_{f}, \sigma_{m}=\mu_{f}+\left(\frac{1-q_{f}}{f}\right) \mu_{q f}, \tau_{z}=\mu_{f}+\left(\frac{q-q_{f}}{f}\right) \mu_{q f}$. Then all markets clear and the pertinent allocation is efficient.

According to proposition 6 there is a unique tax-subsidy scheme to restore efficiency. This scheme consists of the same tax/subsidies $\left(\sigma_{x}, \tau_{m}\right)$ for green product design as in the scenario of proposition 5 , and the pair $\left(\sigma_{m}, \tau_{z}\right)$ is also employed. But since now the market for recycling waste is missing completely, the rates $\left(\sigma_{m}, \tau_{z}\right)$ are greater than in case of proposition 5 , and the four tax rates $\left(\tau_{m}, \sigma_{m}, \sigma_{x}, \tau_{z}\right)$ need to be supplemented by a subsidy on the waste treatment firm's waste input $\left(\tau_{f}<0\right)$ to provide that firm with an appropriate amount of revenue.

Proposition 6 is quite remarkable when compared with proposition 3 . The common feature is that there is no market for recycling waste, but the scenario 
of proposition 6 exhibits the further failure of prices for good $X$ and residuals to reflect material content. In spite of this additional drawback there is a corrective tax-subsidy scheme that does without material content as a tax base whereas such a scheme does not exist in the scenario of proposition 3. A similar observation will be shown to hold when proposition 7 (to be stated below) is compared to its counterpart, proposition 4.

\section{Proposition 7.}

Suppose there is no market for residuals at all and that prices for good $X$ and recycling waste do not depend on their respective material content $\left(P^{z}=P_{q}^{z}=P_{q}^{x}=P_{q_{f}}^{f} \equiv 0\right)$. Set all prices as in proposition 2 , set $\sigma_{x}=-\left(\frac{q}{x}\right) \mu_{q h}, \tau_{m}=-\frac{\mu_{q h}}{x}, \tau_{x}=-\mu_{z}, \sigma_{m}=\left(\frac{1-q}{f}\right) \mu_{q f}-\mu_{z}$,

$\sigma_{f}=\left(\frac{q_{f}-q}{f}\right) \mu_{q f}-\mu_{z}$. Then all markets clear and the pertinent allocation is efficient.

It is worth noting, first of all, that the unique corrective tax-subsidy scheme of proposition 7 also contains the same tax policy $\left(\sigma_{x}, \tau_{m}\right)$ for green product design as the schemes in propositions 5 and 6 . If environmental damage is small, household demand for good $X$ is subsidized to compensate for the revenues forgone from selling residuals on a smoothly working market for residuals $\left(z P^{z}(q)>0\right)$. Otherwise the demand for good $X$ is taxed. In addition, the recycled material and the recycling waste are taxed at positive or negative rates $\left(\sigma_{m} \neq 0, \sigma_{f} \neq 0\right)$ to induce the appropriate material content of recycling waste (while residuals are a free input for the recycler). 
The last market failure we pay attention to is a situation in which the markets for residuals and recycling waste fail simultaneously and completely and in which the price of good $X$ does not depend on material content.

\section{Proposition 8.}

Suppose there are no markets for residuals and recycling waste at all and that the price of good $X$ does not depend on material content $\left(P_{z}=P_{f}=\right.$ $\left.P_{q}^{x}=P_{q}^{z}=P_{q_{f}}^{f} \equiv 0\right)$

(i) Set all other prices as in proposition 2, set $\sigma_{x}=-\left(\frac{q}{x}\right) \mu_{q h}, \tau_{m}=-\frac{\mu_{q h}}{x}$, $\tau_{x}=-\mu_{z}, \tau_{f}=-\mu_{f}, \tau_{z}-\sigma_{f}=\mu_{z}+\mu_{f}+\left(\frac{q-q_{f}}{f}\right) \mu_{q f}$, $\sigma_{m}-\sigma_{f}=\mu_{f}+\left(\frac{1-q_{f}}{f}\right) \mu_{q f}$. Then all markets clear and the pertinent allocation is efficient.

(ii) Suppose the functions $E$ and $R$ take the forms $E\left(\ell_{f}^{d}, q_{f}^{d}, f^{d}\right)=\tilde{E}\left(\ell_{f}^{d}, q_{f}^{d} f^{d}\right)$ and $R\left(\ell_{r}^{d}, q_{r}^{d}, z^{d}\right)=\tilde{R}\left(\ell_{r}^{d}, q_{r}^{d} z^{d}\right)$

(a) Set all other prices as in proposition 2 , set $\sigma_{x}=-\mu_{z}, \tau_{m}=-\frac{\mu_{z}}{q}, \tau_{x}=-\mu_{z}$, $\tau_{f}=-\mu_{f}, \tau_{z}-\sigma_{f}=\mu_{z}+\left(\frac{q}{q_{f}}\right) \mu_{f}, \sigma_{m}-\sigma_{f}=\left(\frac{1}{q_{f}}\right)$. Then all markets clear and the pertinent allocation is efficient.

(b) Set $P^{x}=\mu_{x}-\mu_{z}$, set all other prices as in proposition 2 , set $\tau_{m}=-\frac{\mu_{z}}{q}$, $\tau_{f}=-\mu_{f}, \tau_{z}=\mu_{z}, \sigma_{f}=-\left(\frac{q}{q_{f}}\right) \mu_{f}, \sigma_{m}=\left(\frac{1-q}{q_{f}}\right) \mu_{f}$. Then all markets clear and the pertinent allocation is efficient.

(c) The tax-subsidy scheme in (b) is equivalent to the tax subsidy scheme $\left(\sigma_{b}, \tau_{b}\right.$,

$\left.\sigma_{b f}, \tau_{b f}\right)$ satisfying $\sigma_{b}=\tau_{b}=-\tau_{m}=\frac{\tau_{z}}{q}=\frac{\mu_{z}}{q}$ and $\sigma_{b f}=\tau_{b f}=\left(\sigma_{f}-\sigma_{m}\right)=\frac{\tau_{f}}{q_{f}}$ $=-\frac{\mu_{f}}{q_{f}}$, where $b:=q z$, the material embodied in residuals $z$, is the tax base for $\sigma_{b}$ and $\tau_{b}$ and where $b_{f}:=q_{f} f=q z-r$, the material embodied in recycling waste 
$f$, is the tax base for $\sigma_{b f}$ and $\tau_{b f}$.

As in propositions $5-7$, the policy $\left(\sigma_{x}, \tau_{m}\right)$ in proposition $8(i)$ provides the incentives of firm $X$ for the efficient green design. The other policy parameters $\left(\tau_{x}, \tau_{f}, \tau_{z}, \sigma_{f}, \sigma_{m}\right)$ are needed to achieve the efficient material content of recycling waste using components known from propositions 6 and 7 (and leaving room for some discretion in setting the parameters $\sigma_{f}, \sigma_{m}$ and $\tau_{z}$ ). The tax-subsidy scheme of proposition 8(i) drives wedges between the supplier's and demander's prices for good $X\left(\tau_{x}, \sigma_{x}\right)$, for material $\left(\tau_{m}, \sigma_{m}\right)$, for residuals $\left(\tau_{z}, \sigma_{z}=0\right)$ and for recycling waste $\left(\tau_{f}, \sigma_{f}\right)$ by affecting both sides of the market differently. While the complexity of this scheme certainly casts serious doubts on its practicability it is worth noting that it does not rely on material content as a tax base.

Proposition 8(ii) presents the corrective policy of proposition 8(i) for the special case $E=\tilde{E}$ and $R=\tilde{R}$. As a result of this restriction, the corrective policy parameters are significantly simplified. Observe, in particular, that owing to proposition 1 (iv) the introduction of $\tilde{E}$ and $\tilde{R}$ allows for eliminating $\mu_{q h}$ and $\mu_{q f}$, the Lagrange multipliers referring to material content. This substitution leads to $\tau_{x}=\sigma_{x}=-\mu_{z}$ in proposition $8($ ii)(a) implying that there is no tax wedge on the market for good $X$. Consequently, it is natural to set $\tau_{x}=\sigma_{x}=0$ and redefine the market price for good $X$ in an appropriate way. We derive the tax-subsidy scheme of proposition 8(ii)(b) from that of proposition 8(ii)(a) by setting $\tau_{x}=\sigma_{x}=0$ and by selecting a particular triple $\left(\tau_{z}, \sigma_{f}, \sigma_{m}\right)$ from the set of feasible triples satisfying the equations in proposition 8(ii)(a).

As a consequence of restricting technologies to $\tilde{E}$ and $\tilde{R}$, the tax-subsidy 
scheme of proposition $8(\mathrm{ii})(\mathrm{b})$ is considerably simpler than the scheme of proposition 8(ii)(a). But the main reason for placing special emphasis on it is the important observation of proposition $8($ ii)(c) that for $E=\tilde{E}$ and $R=\tilde{R}$ the tax-subsidy scheme of proposition $8($ ii)(b) is equivalent to quite a different and very simple policy of levying two fees on embodied material. ${ }^{10}$ As is straightforward from the associated Lagrangeans listed in the appendix, the first fee is on the material embodied in good $X$ (to be paid [received] by the producer of good $X$ to [from] the household, if $\mu_{z}$ is negative [positive]), on the material embodied in the residuals (to be paid [received] by the households to [from] the recycler, if $\mu_{z}$ is negative [positive]), and the second fee is on the material embodied in recycling waste, to be paid by the recycler to the waste treatment firm. Interestingly, the fee on embodied material in good $X$ is identical to the fee on embodied material in residuals such that the households are intermediators ('middle men') with respect to embodied materials. In case of a take-back rule that is costless to enforce, administer and monitor, the households would no longer serve the role of intermediators. Correspondingly, the government's intervention would be confined to a fee on material embodied in residuals to be paid by the producer of good $X$ upstream and received by the recycler and a fee on material embodied in recycling waste. In view of proposition $8($ ii $)(c)$ the following points should be stressed:

(i) The two-fee policy of proposition $8($ ii)(c) is not operational unless the material

${ }^{10}$ The only reason why we did not include the fees $\left(\sigma_{b}, \tau_{b}\right)$ and $\left(\sigma_{b f}, \tau_{b f}\right)$ from proposition $8(i i)(c)$ in the Lagrangeans (21)-(25) and in the list of policy parameters in table II is to improve readability of the paper. 
content of residuals and recycling waste is easy to meter. Choosing embodied material as a tax base requires as much information as choosing material content as a tax base. But note also that substituting material content as a tax base by embodied material simplifies the corrective policy.

(ii) The two-fee policy can also be pursued if the technologies do not satisfied $E=\tilde{E}$ and $R=\tilde{R}$. However, in that case the corresponding equilibrium will not be efficient, in general.

(iii) Since, by definition, the fees consist of a tax and a subsidy of the same absolute value imposed on both sides of the transactions under consideration we should expect them to be replaced by market prices provided that the transactions costs are sufficiently low. In other words, the market scenario underlying proposition $8($ ii)(c) (see table III, last line) would then be supplemented by a market for material embodied in residuals (with transactions $b=q z$ ) and by a market for material embodied in recycling waste (with transactions $b_{f}=q_{f} f$ ). The resultant system of competitive markets, quite different from that put forward in Section 4, is capable of implementing an efficient allocation of material (and product design) without the need of any supportive tax-subsidy policy (provided that $E=\tilde{E}$ and $R=\tilde{R}$

As the preceding observations clarified, proposition $8($ ii)(c) opens up a new and surprisingly simple and straightforward corrective policy consisting of two fees, one on material embodied in residuals and the other on material embodied in recycling waste. This policy is efficient if the technologies satisfy $E=\tilde{E}$ and $R=\tilde{R}$. Propositions 3 to 7 did not presuppose that particular technology 
restriction, but if they are reconsidered for $\tilde{E}$ and $\tilde{R}$ it is quite easy to see that if the market for residuals [for recycling waste] fails completely, as in propositions 4 and $7[3$ and 6$]$ then the fee $\left(\sigma_{b}, \tau_{b}\right)$ [the fee $\left.\left(\sigma_{b f}, \tau_{b f}\right)\right]$ from proposition $8($ ii $)(\mathrm{c})$ will perfectly correct for the missing market. While a fee on embodied material is all that is needed in the scenarios underlying propositions 3 and 4 (see table III) the scenarios of propositions 6 and 7 require additional policy parameters to cope with market prices not depending on material content. The fees on embodied material are certainly attractive candidates for corrective policy, but recall that they cannot restore efficiency, in general, unless $E=\tilde{E}$ and $R=\tilde{R}$. It is therefore important to know how realistic this type of technology is. To see that in relevant empirical cases of recycling the technology $\tilde{R}$ cannot be expected to prevail, suppose that $\bar{b}^{d}=q_{r}^{d} z^{d}$ is positive and constant which allows us to choose various combinations of $q_{r}^{d}$ and $z^{d}$ whose product is $\bar{b}^{d}$. Moreover, consider $R=\tilde{R}$ and set $\ell_{r o}^{d}, q_{r_{o}}^{d}$ and $z_{o}^{d}$ positive and constant such that $q_{r o}^{d} \in(0,1)$ and $q_{r o}^{d} z_{o}^{d}=\bar{b}^{d}$. It then follows that $r_{o}^{s}=\tilde{R}\left(\ell_{r o}^{d}, \bar{b}^{d}\right)>0$ with $r_{o}^{s}-\bar{b}^{d}=$ const. $<0$ of recycled material is produced. ${ }^{11}$ Suppose now as a thought experiment $q_{r}^{d}$ is successively reduced and tends to zero while $z^{d}$ is increased such that the product $q_{r}^{d} z^{d}$ still remains $\bar{b}^{d}$. If $\ell_{r_{o}}^{d}$ is kept unchanged the output of recycled material $r_{o}^{s}$ remains constant even when huge amounts of residuals have to be processed to reclaim material from residuals whose material content has become very small. Conversely, we are clearly urged to conclude that the amount of recycled material tends to $r_{o}^{s}=\tilde{R}\left(\ell_{r o}^{d}, \bar{b}^{d}\right)=\bar{b}^{d}$ if $q_{r}^{d}$ tends to one which contradicts $r_{o}^{s}-\bar{b}^{d}=$ const. $<0$ set above (and begs also the question why $\ell_{r_{0}}^{d}>0$ is necessary

\footnotetext{
${ }^{11}$ The exclusion of the limiting value $q_{r o}^{d}=1$ implies $r_{o}^{s}<\bar{b}^{d}$.
} 
to 'regain' material from pure material).

\section{What are the Lessons for Practical Policy?}

The preceding analysis reexamined the issue of allocating a natural resource, called material, that is first extracted and then used for producing a consumption good. After consumption and recycling, the recycling waste is treated prior to landfilling to reduce environmental damage. The material embodied per unit of consumption good affects the productivity of recycling, and hence the choice of material content constitutes an important aspect of green product design. The second novel aspect is an efficiency issue in the choice of material content in recycling waste that the recycling firm passes on to the waste treatment firm. Both types of material content are decisive economic variables affecting the agents at different stages of material processing.

Based on Eichner and Pethig [2] a competitive market system is put forward as a benchmark. Since efficiency is attained with a complete set of active markets, the material allocation is obviously inefficient if some of the constituent markets don't operate smoothly or even fail to be active, unless some corrective taxsubsidy scheme bridges the gap. Our analysis of market failure and corrective tax/subsidy schemes leaves us with a disturbing complexity and variety of policy options. To some extent the analysis of Section 5 above is not immediately focused at practical policy advice but rather investigates the capacity of various sets of price (or rather tax and subsidy) signals to direct material flows efficiently. This informs us about what the potential levers of corrective actions are, it gives us 
some indirect information about the allocative distortions to be expected in the absence of those signals, and it should also lead us to step beyond the formal model to address chances of and limits to policy implementation based on our theoretical results.

Before we discuss this issue in more detail it appears appropriate to recall that the complexity of corrective policies derived from the formal model is partly due to the simultaneous consideration of both recycling and waste management. Even though for some types of solid waste only one of both modes of waste processing is relevant, we chose to follow the two-stage processing approach since it allowed to identify various complexity-increasing feedbacks and repercussions of policy action. To single out scenarios where either recycling or waste treatment is absent is straightforward and therefore left to the reader. But since both stages of waste processing are often linked (via $q$ and $q_{f}$, in our model) the policy message is that efficiency-oriented policy requires an integrated approach.

Suppose now, the market for residuals and/or recycling waste fails completely to be active. Our discussion in Section 5 showed that three different corrective policies are available:

( $\alpha$ ) A two-part fee is levied consisting of a fee per unit of residuals [recycling waste] and a fee based on material content of residuals [recycling waste].

( $\beta$ ) A fee per unit of residuals [recycling waste] is levied that depends on the material content of residuals [recycling waste] and that replaces exactly the missing price $P^{z}(q)\left[P^{f}\left(q_{f}\right)\right]$

$(\gamma)$ A fee per unit of material embodied in residuals [recycling waste] is levied. 
Since in policy $(\alpha)$ two fees are needed to replace each missing market, this policy is more difficult to administer than the policies $(\beta)$ and $(\gamma)$. Moreover, Eichner and Pethig [2] show that as a precondition for efficiency the fees based on material content have to be 'personalized' when the analysis is extended to the case of many agents. Or else, fees that are uniform across agents would introduce a distortion. Consequently, the policies $(\beta)$ and $(\gamma)$ appear to be more attractive, even though they don't come without some drawbacks either: According to Eichner and Pethig [2], policy $(\beta)$ is not efficient in a multi-agent economy, unless $E=\tilde{E}$ and $R=\tilde{R}$ which is also required for policy $(\gamma)$ to be efficient. Given this similarity, the per-unit fee of policy $\gamma$ appears easier to administer than a schedule of rates of a fee that vary with material content. In conclusion, the policy $(\gamma)$ appears to be recommendable when it can be expected (i) that the allocative displacement effects of the technologies $E$ and $R$ when deviating from $\tilde{E}$ and $\tilde{R}$ are not too severe and (ii) and that the use of 'embodied material' (or 'material content', for that matter) as a tax base is not too complicated and expensive to administer.

In Section 5 we also paid attention to the options for corrective action in case that material content cannot be used as a tax base. No such option turned out to exist, if the market failure is restricted to a complete break-down of the market for residuals or of the market for recycling waste. Since the policies of propositions 3 and 4 are more complicated than policy $(\gamma)$ they do not appear to be of practical relevance if material content or embodied material can be taxed.

Quite surprisingly, if markets fail to reflect material content in their prices as in the scenarios underlying the propositions 5 to 8 (see table III) corrective 
tax/subsidy schemes could be specified that do not tax or subsidize material content. In that context the policy for green product design deserves special mention which emerges consistently in the propositions 5 to 8 . Either the output is taxed and the material input is subsidized or vice versa depending on whether an increase or a reduction of material content is to be induced. On the whole, however, the complexity of the corrective policies available in those market scenarios is severe so that these tax/subsidy schemes can hardly be considered candidates for practical waste policy. Standards for product design and material content or recycling quotas appear to be instruments which one might want to consider as alternatives to complicated tax/subsidy incentives if material content is not taxable.

To see that embodied material is, in fact, used as a basis for fees levied in practical solid waste management we briefly consider the 'Duales System Deutschland' (DSD), compare Staudt, Kunhenn, Scholl and Interthal [19], that is a private producer responsibility organization managing all non-industrial packaging waste in Germany. Clearly, our model does not contain the specificities of the German institutional setting of take-back requirements and government regulation in which the DSD operates. But none-the-less, it is instructive to know that the fees laid down by the DSD tend to be based on embodied material. To be more specific, all firms that use packages for their consumption goods (here: the producer of good $X$ ) pay fees that are material-specific, hence based on embodied material $\left(\sigma_{b}\right)$ as well as on the weight of the per-unit package $\left(\sigma_{x}\right)$. In addition, the recyclers (or rather the sorting firm in case of the DSD) are paid by the DSD a material-specific subsidy which is based, approximately, on embodied material 
$\left(\tau_{b}\right)$ and which is high enough to also cover the fee due for treating or depositing sorting waste.

We simplified our analysis by assuming that enforcement against illegal disposal is costless. Relaxing this assumption would tend to render policies of administrative prices inefficient which are otherwise efficient since the suppliers of 'bads' have an incentive for illegal dumping if the bads are negatively priced. Recyclers face such an incentive regarding recycling waste but also households if the price of residuals is negative (which is a possibility as shown in the discussion of proposition 2). It should be also noted, however, that little consensus has been reached in the literature what the extent of allocative disruption through illegal dumping is if 'bads' carry negative price tags and enforcement is incomplete. After all, some amount of illegal disposal occurs under any system of recycling and landfilling. The merits of different arrangements would than have to be determined by complex comparative institutional analyses.

A final remark relates to the present paper's exclusive focus on perfectly competitive markets and on policy options in case of market failure. Imperfect competition is an important feature in the area of solid waste processing since the spatial dimension and the associated transaction costs are likely to create local oligopolies or even monopolies. It is an important topic for future research to investigate the impact of imperfect competition on efficient resource management. Another limitation of the paper is to exclude vertical integration. If, for example, recycling and waste treatment is done by one and the same firm, profit maximization would internalize any externality thus yielding the efficient material content of recycling waste. One can also imagine that both the production of 
the consumption good and recycling is done by the same firm thus eliminating the product-design externality. But note that the more widespread mergers of this kind are the greater tends to be the deviation from perfect competition. Therefore, vertical integration is not likely to be the solution to all management problems of recycling and waste treatment.

\section{Appendix}

Economy (1)-(14) with taxes and subsidies for embodied material

$$
\begin{gathered}
\hat{\mathcal{L}}^{H}=U\left(e, \ell^{s}, x^{d}\right)+\gamma_{c}\left[p_{\ell} \ell^{s}+\phi+\sigma_{b} b_{h}^{s}-P^{x} x^{d}-\tau_{b} b_{h}^{d}\right] \\
+\gamma_{s}\left(b_{h}^{s}-q z^{s}\right)+\gamma_{g}^{s}\left(z^{s}-x^{d}\right), \\
\hat{\mathcal{L}}^{P}=P^{x} x^{s}+\sigma_{b} b_{x}^{s}-p_{\ell} \ell_{x}^{d}-p_{m} m^{d}+\gamma_{x}\left[X\left(\ell_{x}^{d}, m^{d}\right)-x^{s}\right]+\gamma_{q}\left(q-\frac{m^{d}}{x^{s}}\right) \\
+\gamma_{b}\left(b_{x}^{s}-q x^{s}\right), \\
\hat{\mathcal{L}}^{E}=-t_{e} e-p_{\ell} \ell_{f}^{d}-\tau_{b f} b_{f}^{d}+\gamma_{e}\left[e-E\left(\ell_{f}^{d}, q_{f}, f^{d}\right)\right]+\gamma_{q f}\left(b_{f}^{d}-q_{f} f^{d}\right), \\
\hat{\mathcal{L}}^{R}=p_{m} r^{s}-p_{\ell} \ell_{r}^{d}-\tau_{b} b_{r}^{d}+\sigma_{b f} b_{f}^{s}+\gamma_{r}\left[R\left(\ell_{r}^{d}, q, z^{d}\right)-r^{s}\right]+\gamma_{b q}\left(b_{r}^{d}-q z^{d}\right) \\
+\gamma_{b f}\left(q z^{d}-r^{s}-b_{f}^{s}\right),
\end{gathered}
$$

and (25).

\section{Proof of proposition 1:}

Equation (16) follows immediately from ${ }^{12}$ (I.1.1) and (I.1.7). To establish equation (17) we insert (I.1.4) and (I.1.6) in (I.1.5). Then we obtain after some

${ }^{12}$ Reference to equations in a table is made by (a.b.c), where $\mathrm{a}$ is the table, $\mathrm{b}$ is the column, and $c$ is the row. 
rearrangements $\mu_{q h}=-x\left(\frac{X_{m}}{X_{\ell}}-\frac{1}{V_{\ell}}\right)=-\frac{x A}{X_{\ell}}$. Combining (I.1.7) and (I.1.9) leads to $\mu_{q f}=-\frac{E_{q_{f}}}{E_{\ell}}$ and combining (I.1.10) and (I.1.12) we get $\mu_{q c}=\frac{R_{q}}{R_{\ell}}-\mu_{q f} \frac{z}{f}$. Since $\mu_{q c}=\mu_{q h}$ via (I.1.3), equation (17) is straightforward.

In order to derive (18) we plug $\mu_{x}=\frac{1}{X_{\ell}}+\mu_{q h} \frac{q}{x}$ from (I.1.4) and $\mu_{z}=\frac{R_{z}}{R_{\ell}}$ $-\mu_{f}-\mu_{q f}\left(\frac{q-q_{f}}{f}\right)$ from (I.1.10) and (I.1.11) in (I.1.2) which yields under consideration of $\mu_{f}=-\frac{E_{f}}{E_{\ell}}, \mu_{q f}=-\frac{E_{q_{f}}}{E_{\ell}}$ and $\mu_{q h}=\frac{R_{q}}{R_{\ell}}-\mu_{q f} \frac{z}{f}$ after some rearrangements $-\frac{U_{x}}{U_{\ell}}=\frac{1}{X_{\ell}}+\frac{R_{q}}{R_{\ell}} \frac{q}{z}-\frac{R_{z}}{R_{\ell}}-\frac{E_{f}}{E_{\ell}}-\frac{E_{q_{f}}}{E_{\ell}}\left[\frac{q-q_{f}}{f}-\frac{z}{f} \frac{q}{z}\right]$. Since the term in rectangular brackets can be simplified to $-\frac{q_{f}}{f}$, we obtain (18).

To prove proposition 1 (ii), observe that by definitions of $\tilde{E}$ and $\tilde{R}$ we have $E_{f}=\tilde{E}_{b} q_{f}, E_{q_{f}}=\tilde{E}_{b} f$ where $\tilde{E}_{b}:=\frac{\partial \tilde{E}}{\partial\left(q_{f}^{d} f^{d}\right)}$ and $R_{z}=\tilde{R}_{m} q, R_{q}=\tilde{R}_{m} z$ where $\tilde{R}_{m}:=\frac{\partial \tilde{R}}{\partial\left(q_{r}^{d} z^{d}\right)}$. Using the partial derivatives of $\tilde{E}$ and $\tilde{R}(18)$ implies $-\frac{U_{x}}{U_{\ell}}=\frac{1}{X_{\ell}}+\frac{\tilde{R}_{m}}{\tilde{R}_{\ell}}\left[z \frac{q}{z}-q\right]-\frac{\tilde{E}_{b}}{\tilde{E}_{\ell}}\left[q_{f}-f \frac{q_{f}}{f}\right]$.

We now proceed to prove proposition 1(iii). Recall that $A=X_{m}-\frac{X_{\ell}}{V_{\ell}}$. The assumptions linear homogenity of the function $X$ and linearity of $V$ ensure that $V_{\ell}=$ const., and that there is a function $F$, strictly concave and increasing, such that $F(k)=\frac{1}{q}$ where $k:=\frac{\ell_{x}}{m}$. Since $X_{\ell}=F_{k}$ is strictly decreasing and $X_{m}$ is strictly increasing in $k, A$ is strictly increasing in $k . F_{k}>0$ and $F(k)=\frac{1}{q}$ imply that there exists a function $A=\varphi^{-1}(q)$ which is strictly decreasing in $q$. Then using the inverse function of $\varphi^{-1}$ we get the statement of proposition 1(iii).

Finally, we prove proposition 1(iv). Combining (I.1.8) with (I.1.9) leads to

$$
\mu_{q f}=\mu_{f} \frac{E_{q_{f}}}{E_{f}}
$$

Inserting $E_{f}=\tilde{E}_{b} q_{f}$ and $E_{q_{f}}=\tilde{E}_{b} f$ clearly yields $\frac{\mu_{q f}}{f}=\frac{\mu_{f}}{q_{f}}$. To derive $\frac{\mu_{q h}}{z}=\frac{\mu_{z}}{q}$ 
recall that $\mu_{z}=\frac{R_{z}}{R_{\ell}}-\mu_{f}-\mu_{q f}\left(\frac{q-q_{f}}{f}\right) . \quad \mu_{z}$ can be rearranged to $\mu_{z}=\frac{R_{z}}{R_{\ell}}$ $-\frac{q}{f} \mu_{q f}-\mu_{f}+\mu_{q f} \frac{q_{f}}{f} . \quad$ Substituting $\mu_{q f}=\left(\frac{R_{q}}{R_{\ell}}-\mu_{q c}\right) \frac{z-r}{z}, \mu_{f}=-\frac{E_{f}}{E_{\ell}}$, and $\mu_{q f}=-\frac{E_{q_{f}}}{E_{\ell}} \operatorname{turn} \mu_{z}$ into

$$
\mu_{z}=\frac{R_{z}}{R_{\ell}}-\frac{R_{q}}{R_{\ell}} \frac{q}{z}+\mu_{q c} \frac{q}{z}+\frac{E_{f}}{E_{\ell}}-\frac{E_{q_{f}}}{E_{\ell}} \frac{q_{f}}{f} .
$$

Applying the partial derivatives of $\tilde{E}$ and $\tilde{R}$ we find that $\frac{R_{z}}{R_{\ell}}-\frac{R_{q}}{R_{\ell}} \frac{q}{z}=0$ and $\frac{E_{f}}{E_{\ell}}-\frac{E_{q_{f}}}{E_{\ell}} \frac{q_{f}}{f}=0$ which completes the proof of $(20)$.

To show that (20) does not hold, in general, if $E \neq \tilde{E}$ and $R \neq \tilde{R}$, consider the class of functions $\breve{E}$ and $\breve{R}$ specified by $\breve{E}\left(\ell_{f}, q_{f}^{d} f^{d}, q_{f}^{d}\right)$ and $\breve{R}\left(\ell_{r}, q_{r}^{d} z^{d}, q_{r}^{d}\right)$. We define $\breve{E}_{b}:=\frac{\partial \breve{E}}{\partial\left(q_{f}^{d} f^{d}\right)}, \breve{R}_{m}:=\frac{\partial \breve{R}}{\partial\left(q_{r}^{d} z^{d}\right)}$, and obtain the derivatives $E_{q_{f}}=\breve{E}_{b} f+$ $\breve{E}_{q f}, E_{f}=\breve{E}_{b} q_{f}, R_{q}=\breve{R}_{m} z+\breve{R}_{q}$, and $R_{z}=\breve{R}_{m} q$ which turn (A9) and (A10) into $\mu_{q f}=\mu_{f} \frac{f}{q_{f}}+\frac{\breve{E}_{q_{f}}}{\breve{E}_{b} q_{f}}$ and $\mu_{z}=-\frac{\breve{R}_{q}}{\breve{R}_{\ell}} \frac{q}{z}-\frac{\breve{E}_{q_{f}}}{\breve{E}_{\ell}} \frac{q_{f}}{f}+\mu_{q c} \frac{q}{z}$, respectively. The last equations contradict (20) whenever $\breve{R}_{q} \neq 0$ and $\breve{E}_{q_{f}} \neq 0$. (Q.e.d.)

\section{References}

1. T. M. Dinan, Economic efficiency effects of alternative policies for reducing waste disposal, J. Environ. Econom. Management 25, 242-256 (1993).

2. T. Eichner and R. Pethig, 'Product design and alternative market schemes for solid waste treatment and disposal', Discussion Paper 73-99, University of Siegen (1999).

3. D. Fullerton and T. Kinnaman, Garbage, recycling, and illicit burning or dumping, J. Environ. Econom. Management 29, 78-91 (1995). 
4. D. Fullerton and W. Wu, Policies for green design, J Environ. Econom. Management 36, 131-148 (1998).

5. J. Highfill and M. McAsey, Municipal waste management: recycling and landfill space constraints, J. Urban Econom. 41, 118-136 (1997).

6. K. Holm-Mueller, Die Verwertung des deutschen Abfallrechts im Lichte des Material-Bilanz-Ansatzes, Jahrbuch der Wirtschaftswissenschaften 47, 311$323(1996)$.

7. S. Holterman, Alternative tax systems to correct for externalities, and the efficiency of paying compensation, Economica 43, 1-16 (1976).

8. A. Huhtala, A post-consumer waste management model for determining optimal levels of recycling and landfilling, Environ. Res. Econ. 10, 301$314(1997)$

9. R. E. Kohn, Convex combinations of recycling incentives, Mathematical Computation Modelling 21, 13-21 (1995).

10. R. Lusky, A model of recycling and pollution control, Canad. J. Econom. 9, 91-101 (1976).

11. A. K. Miedema, Fundamental economic comparisons of solid waste policy options, Resources and Energy 5, 21-43 (1983).

12. G. Morris and D. M. Holthausen, The economics of household solid waste generation and disposal, J. Environ. Econom. Management 26, 215-234 (1994).

13. K. Palmer, H. Sigman, and M. Walls, The costs of reducing municipal solid 
waste, J. Environ. Econom. Management 33, 128-150 (1997).

14. K. Palmer and M. Walls, Optimal policies for solid waste disposal: taxes, subsidies, and standards, J. Public Econom. 65, 193-205 (1997).

15. R. Pethig, 1977, International markets for secondary material, in 'Resource Conservation: Social and Economic Dimensions of Recycling' (D. W. Pearce and I. Walter, Eds.), New York University Press, New York, 191-206, 353$383(1970)$.

16. A. S. Rousso and S. P. Shah, Packaging taxes and recycling incentives: the german green dot programm, National Tax J. 47, 689-701 (1994).

17. H. Sigman, A comparison of public policies for lead recycling, RANDJ. Econom. 26, 452-478 (1995).

18. V. L. Smith, Dynamics of waste accumulation: disposal versus recycling, Quart. J. Econom. 86, 600-616 (1972).

19. E. Staudt, H. Kunhenn, M. Scholl, and J. Interthal, 'Die Verpackungsordnung. Auswirkungen eines umweltpolitischen Grossexperimentes', Innovation: Forschung und Management, Band 11, Bochum (1997). 


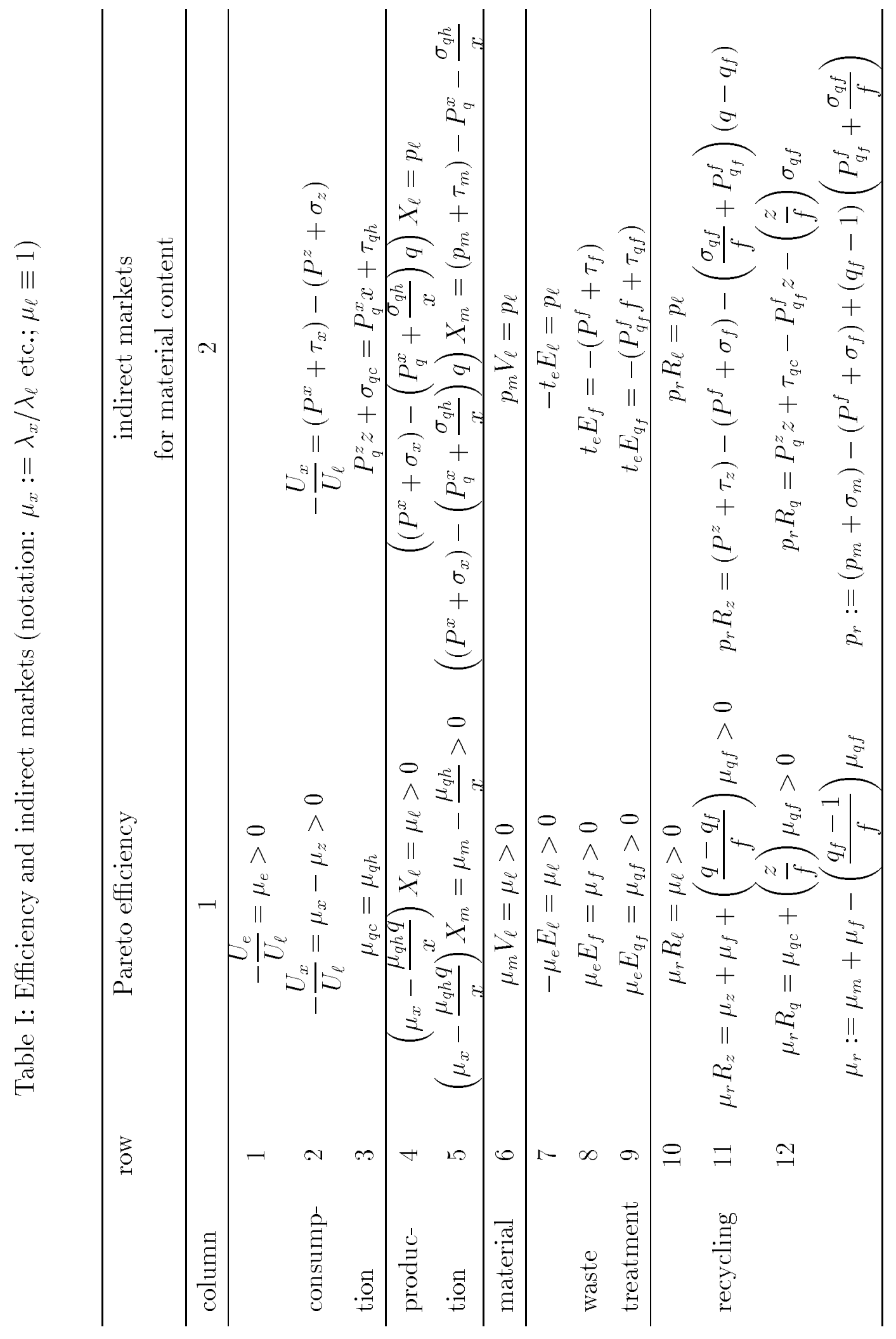


Table II: Prices and policy instruments

\begin{tabular}{|c|c|c|c|}
\hline \multicolumn{2}{|l|}{ (marketed) goods } & \multirow{2}{*}{$\begin{array}{c}\text { market prices } \\
2 \\
\end{array}$} & \multirow{2}{*}{$\begin{array}{c}\text { policies } \\
3\end{array}$} \\
\hline & 1 & & \\
\hline labour & $\ell^{s}, \ell_{x}^{d}, \ell_{r}^{d}, \ell_{f}^{d}, \ell_{v}^{d}$ & $p_{\ell}$ & - \\
\hline \multirow{3}{*}{ material } & $v^{s}$ & \multirow{3}{*}{$p_{m}$} & - \\
\hline & $r^{s}$ & & $\sigma_{m}$ \\
\hline & $m^{d}$ & & $\tau_{m}$ \\
\hline \multirow{2}{*}{ good $X$} & $x^{s}$ & \multirow{2}{*}{$P^{x}(q)$} & $\sigma_{x}$ \\
\hline & $x^{d}$ & & $\tau_{x}$ \\
\hline \multirow{2}{*}{ residuals } & $z^{s}$ & \multirow{2}{*}{$P^{z}(q)$} & $\sigma_{z}$ \\
\hline & $z^{d}$ & & $\tau_{z}$ \\
\hline \multirow{2}{*}{ recycling waste } & $f^{s}$ & \multirow{2}{*}{$P^{f}\left(q_{f}\right)$} & $\sigma_{f}$ \\
\hline & $f^{d}$ & & $\tau_{f}$ \\
\hline \multirow{2}{*}{ material content of good $X$} & $q_{x}^{s}$ & - & $\sigma_{q h}$ \\
\hline & $q_{h}^{d}$ & - & $\tau_{q h}$ \\
\hline \multirow{2}{*}{ material content of residuals } & $q_{h}^{s}$ & - & $\sigma_{q c}$ \\
\hline & $q_{r}^{d}$ & - & $\tau_{q c}$ \\
\hline \multirow{2}{*}{ material content of recycling waste } & $q_{f}^{s}$ & - & $\sigma_{q f}$ \\
\hline & $q_{f}^{d}$ & - & $\tau_{q f}$ \\
\hline pollution & $e$ & - & $t_{e}$ \\
\hline
\end{tabular}

Table III: Scenarios of market failure

\begin{tabular}{|c|c|c|c|c|c|c|c|c|}
\hline \multirow{2}{*}{$\begin{array}{l}\text { Prop. } \\
\text { No.: }\end{array}$} & \multirow{2}{*}{$P^{f} \equiv 0$} & \multicolumn{2}{|c|}{$P^{f} \neq 0$} & \multirow[t]{2}{*}{$P^{z} \equiv 0$} & \multicolumn{2}{|c|}{$P^{z} \neq 0$} & \multicolumn{2}{|c|}{$P^{x}>0$} \\
\hline & & $P_{q_{f}}^{f} \equiv 0$ & $P_{q_{f}}^{f} \neq 0$ & & $P_{q}^{z} \equiv 0$ & $P_{q}^{z} \neq 0$ & $P_{q}^{x} \equiv 0$ & $P_{q}^{x} \neq 0$ \\
\hline 3 & $\mathrm{x}$ & & & & & $\mathrm{x}$ & & $\mathrm{x}$ \\
\hline 4 & & & $\mathrm{x}$ & $\mathrm{x}$ & & & & $\mathrm{x}$ \\
\hline 5 & & $\mathrm{x}$ & & & $\mathrm{x}$ & & $\mathrm{x}$ & \\
\hline 6 & $\mathrm{x}$ & & & & $\mathrm{x}$ & & $\mathrm{x}$ & \\
\hline 7 & & $\mathrm{x}$ & & $\mathrm{x}$ & & & $\mathrm{x}$ & \\
\hline 8 & $\mathrm{x}$ & & & $\mathrm{x}$ & & & $\mathrm{x}$ & \\
\hline
\end{tabular}


Table IV: Tax-subsidy schemes in case of $P^{f} \equiv 0$ and $P_{q_{f}}^{f} \equiv 0$.

\begin{tabular}{ccccc}
\hline & policy (a) & policy (b) & policy (c) & policy $(\mathrm{d})$ \\
\hline$P^{z}$ & $\mu_{z}$ & $\mu_{z}$ & $\mu_{z}+\mu_{f}$ & $\mu_{f}+\frac{\left(q-q_{f}\right) \mu_{q f}}{f}$ \\
$\tau_{q f}$ & $-\mu_{q f}$ & $-\mu_{q f}$ & $-\mu_{q f}$ & $-\mu_{q f}$ \\
$\sigma_{q f}$ & $-\mu_{q f}$ & $-\mu_{q f}$ & $-\mu_{q f}$ & 0 \\
$\tau_{f}$ & $-\mu_{f}$ & $-\mu_{f}$ & $-\mu_{f}$ & $-\mu_{f}$ \\
$\sigma_{f}$ & $-\mu_{f}$ & 0 & 0 & 0 \\
$\sigma_{m}$ & 0 & $\mu_{f}$ & $\mu_{f}$ & $\mu_{f}-\frac{q_{f} \mu_{q f}}{f}$ \\
$\tau_{z}$ & 0 & $\mu_{f}$ & 0 & 0 \\
$\tau_{x}$ & 0 & 0 & $\mu_{f}$ & $\mu_{f}+\frac{\left(q-q_{f}\right) \mu_{q f}}{f}$ \\
$\tau_{q c}$ & 0 & 0 & 0 & $\frac{z \mu_{q f}}{f}$ \\
\hline
\end{tabular}

Symbols:

A production distortion

$b \quad$ material embodied

$e \quad$ environmental damage

$f \quad$ recycling waste

$\ell \quad$ labour

$m \quad$ material

$p \quad$ price

$P \quad$ price function

$q \quad$ material content

$r \quad$ recycled material

$t_{e} \quad$ emission tax

u utility

$v \quad$ virgin material

$x \quad$ consumption good

$z \quad$ residual

$\gamma, \lambda, \mu, \pi \quad$ Lagrange multiplier

$\tau, \sigma \quad$ policy instrument

$\phi \quad$ lumpsum transfer 